\title{
Section properties of palm petioles, Part 2: The relationship of petiole histology with the torsional rigidity of the palm, Trachycarpus fortunei
}

\author{
A.G.Windsor-Collins ${ }^{1}$, M.A.Atherton ${ }^{1}$, M.W.Collins ${ }^{1} \&$ \\ D.F.Cutler ${ }^{2}$ \\ ${ }^{1}$ School of Engineering \& Design, Brunel University, United Kingdom. \\ ${ }^{2}$ Royal Botanic Gardens, Kew, United Kingdom.
}

\begin{abstract}
The Trachycarpus fortunei palm is a good example of a palm with a large leaf blade supported by a correspondingly large petiole. The interaction of the material and functional properties of the petiole was analysed using engineering and botanical methods with a view to understanding how the petiole functions from a structural standpoint. The histological aspects of the petiole were analysed from sections taken at regular intervals along the petiole axis, in order to determine the density and position of the vascular bundles. A modified torsion rig was then used to acquire torsion readings and calculate the rigidity modulus variation along the petiole. To supplement this, shape factor derived data from the Trachycarpus fortunei palm petiole were calculated and then compared with the empirical results and the differences analysed.
\end{abstract}

Keywords: palm petiole, vascular bundle, axial torque, geometry, rigidity modulus, composite, material properties, torsion, shear stress, cross section efficiency, evolution, shape factor, dicotyledon, monocotyledon, parenchyma 


\section{Introduction}

The largest blades in the plant kingdom may be found in Arecaceae (the palm family) providing a reason for exploration into their structure and engineering properties. The palm Trachycarpus fortunei was chosen for the empirical analysis because of its overall large size (up to about $12 \mathrm{~m}$ high), and its correspondingly large leaves of up to one metre in diameter [1]. Theoretical aspects of the constructal structure are also investigated. This palm is native to China and the Himalayas, thriving in temperate regions and is one of the world's hardiest palms. A popular name for it is the Chinese windmill palm because its leaves are stiff and fan-shaped, like a windmill. It has a slender single stem of about $250 \mathrm{~mm}$ in diameter and is typically slightly narrower at the base than at the top. Environmental factors such as wind and rain acting on the blade generate combined flexural and torsion loads on the petiole. How do the section properties of the petiole deal with this loading?

Palm petiole cross section efficiency was examined using modelled petiole profiling data for Trachycarpus fortunei. This was achieved by calculating the torsional characteristics along six equidistant points along the petiole axis. The cross section of petioles generally changes from being grooved on the upper (adaxial) surface to either angular, cylindrical or rhombohedral towards the distal end [2], these organic forms being more complex than regular shaped bodies.

Gibson et al [3] state that for beams and plates of a given stiffness or strength, or for a column of a given buckling resistance, palms (as well as woods and bamboos) are among the most efficient natural materials available owing to their composite and cellular microstructures. The petiole of the palm Chamaerops humilis analysed in [3] was found to have a radially uniform distribution of vascular bundles within a parenchyma matrix. The petiole was modelled as a unidirectional fibre composite, with a uniform distribution of fibres in a honeycomb matrix of the same solid material. Such structures are common in many palm 'petioles' and stems in other monocotyledonous species. By varying the volume fraction of fibres radially in a fibre composite of circular cross section they came to the conclusion that a non-uniform distribution leads to an increased flexural rigidity over a uniform distribution. They also found that further increases in rigidity were possible if the cross section is hollow like bamboo, whereas a thin walled tube gained little from a structural gradient.

Trachycarpus fortuneii like some other palms however, has vascular bundles that are concentrated radially towards the outside of the petiole [4]. The tensile modulus of palm vascular bundles is remarkable at 100GPa [5]. Sclerenchyma (derived from the word 'scleros' in Greek meaning 'hard') is the lignified tissue that partially or entirely surrounds the vascular bundles which in effect forms tubes. 


\section{Petiole histology}

In order to evaluate the internal structure of the petiole, cut sections were mounted in wax and scanned at a resolution of 1200dpi. This revealed the arrangement of vascular bundles. Three-centimetre samples were cut at six equal intervals (of $171 \mathrm{~mm}$ ) along the petiole axis ending at where the leaf blade joined the petiole (sample P6) as shown in fig.1. It is important to note here that the scanned sections are labelled P1 to P6 and that the segments A, B and C refer to the torsion experiments.

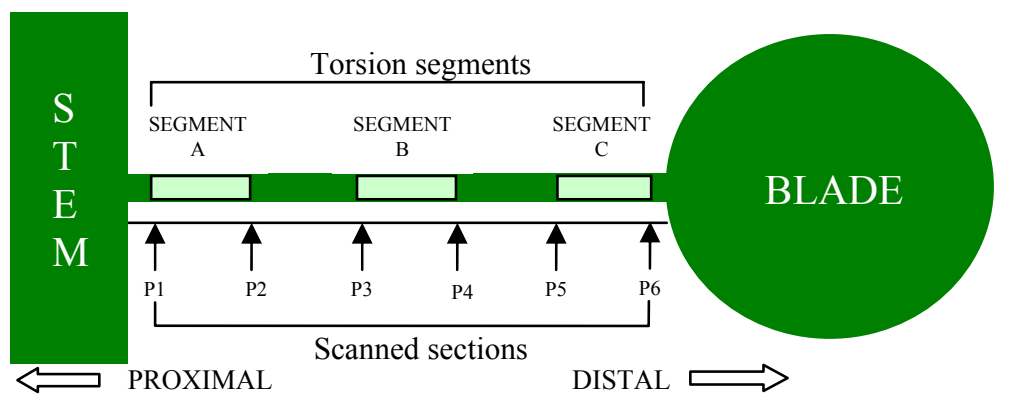

Figure 1: Palm petiole schematic showing the relative placement of scanned sections $\mathrm{P} 1$ to $\mathrm{P} 6$ and segments $\mathrm{A}, \mathrm{B}$ and $\mathrm{C}$ for the torsion experiments.

\subsection{Section scanning}

Fig. 2 reveals that the remainder of each section embedded in the wax after removal of some cross section slices with the microtome (providing a clean cut surface), was enough to use a scanner to analyse the placement and number of vascular bundles.

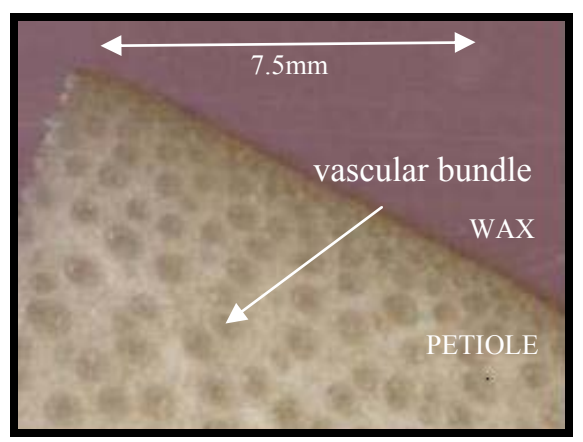

Figure 2: Part of section P6 showing a higher concentration of vascular bundles towards the petiole / air boundary. See figure 3 for typical petiole section dimension. 
Each section was scanned at $1200 \mathrm{dpi}$ and a $0.25 \mathrm{~mm}$ grid placed over them using Adobe Photoshop ${ }^{\circledR}$ software. Sections P1 and P6 are shown in fig.3:
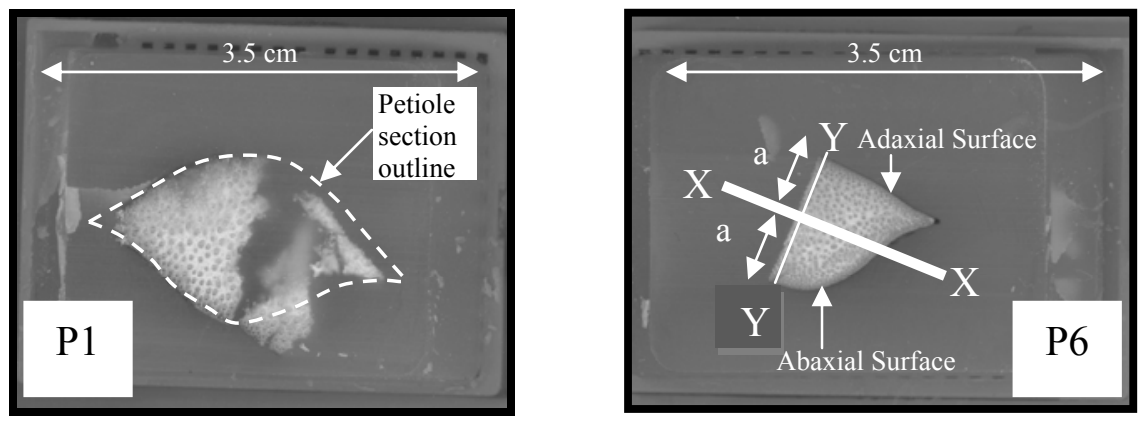

Figure 3: Photograph showing sections P1 (nearest the palm stem) and P6 (nearest the blade) embedded in wax. Sample P1 was torn while cutting the hard sample using a scalpel. Lines XX and YY are used for reference later where XX perpendicularly bisects YY.

\subsection{Vertical vascular bundle distribution within petiole}

The petiole may be described as a compound cantilever. It is compound as the vascular bundles which have relatively high tensile strength are situated within the comparatively weak surrounding parenchyma matrix. The tensile modulus of palm vascular bundles is impressively high at $100 \mathrm{GPa}$ [5] compared to Kevlar which ranges from 83 to $186 \mathrm{GPa}$ (grades 29-149). From a structural standpoint, the vascular bundles may be likened to reinforcing rods embedded within concrete, forming reinforced concrete.

The thin white line YY shown in fig. 3 section P6 runs between the adaxial and abaxial surfaces of the section at its thickest point. The thicker white line, $\mathrm{XX}$ also shown in fig. 3 perpendicularly bisects YY. The vascular bundles on either side of Line XX were counted with the aid of a graticule and it was found that there were $47 \%$ more vascular bundles on the adaxial side of Line XX than abaxial to it. Further to this, $80 \%$ of the cross sectional area of petiole section P6 was found to be adaxial to Line XX. The result of this is that there is a higher density of vascular bundles on the underside (abaxial side) of the petiole at section P6 nearest the leaf blade. It would be interesting to look at this distribution for sections P1 to P5 to obtain a distribution along the petiole and integrate this with the radial distribution analysis in section 2.3.

\subsection{Radial vascular bundle distribution within petiole}

The density (area concentration) of vascular bundles was calculated by counting the number of vascular bundles per $2.5 \mathrm{~mm}^{2}$ using a square shaped graticule. This procedure was followed for the entire viewable area of each sections. The mean average vascular bundle density was determined by counting 
the number of vascular bundles within the graticule squares positioned entirely internally within the petiole cross section and at the same time, at distances greater than $1 \mathrm{~mm}$ from the petiole surface as there is a much higher density of vascular bundles near the section surfaces. When the graticules were placed in the most internal half of the petiole and the vascular bundles counted, the vascular bundles were labelled 'internal' and those in the half nearer the edge of the petiole were called 'peripheral'.

\subsection{Axial vascular bundle distribution within petiole}

The results in fig. 4 show that the area concentration of both the peripheral and internal vascular bundles increased fairly uniformly towards the leaf blade. One would expect this if the number of vascular bundles in sections remained the same whilst the section areas decreased. However, this increase was not a result of the reducing section area alone. The number of vascular bundles in the cross section increased distally. This was shown in that the number of vascular bundles in section P4 was 330, and in section P6 was 375, revealing an increase of $13 \%$ of vascular bundles over a third of the petiole length.

Interestingly, the gradients of the trend lines indicated that the concentration of the peripheral vascular bundles increases more per unit axial distance than that of the internal bundles. This creates the effect of the petiole becoming more tube like towards the leaf providing the petiole with varying torsion and bending characteristics.

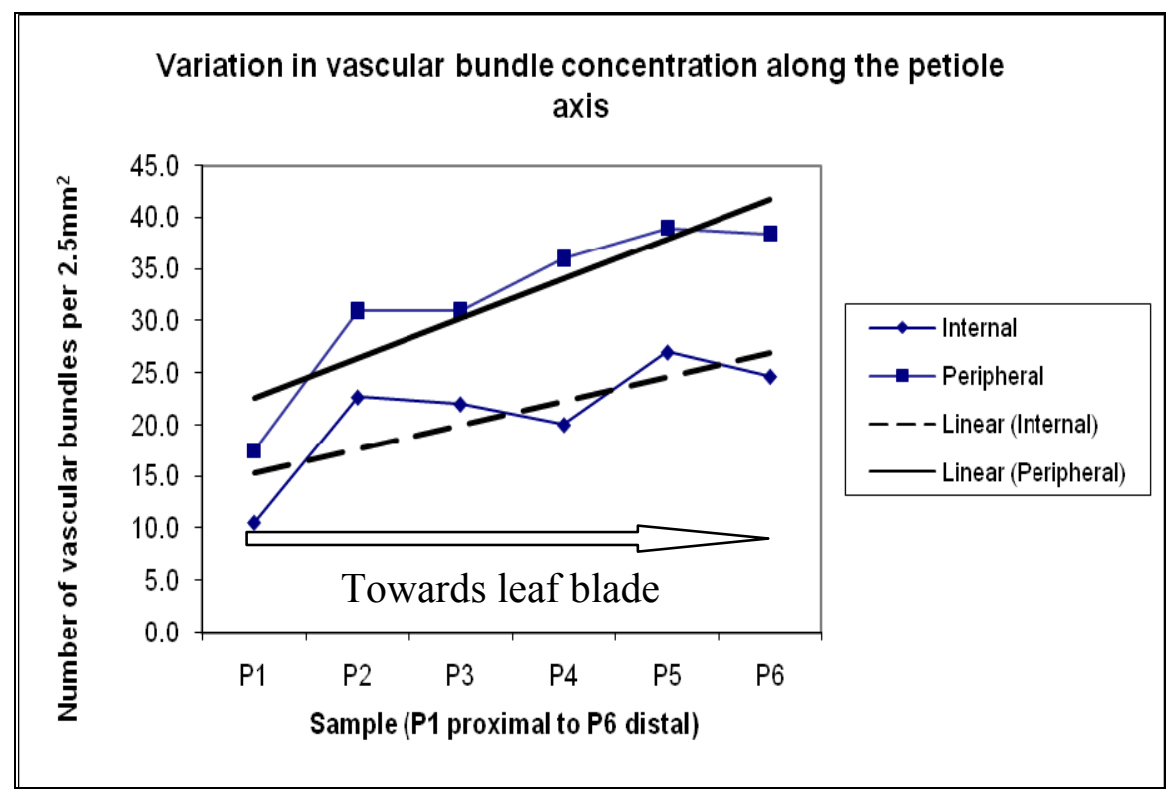

Figure 4: The variation of vascular bundle concentration along the petiole axis. 


\section{Torsion tests}

The external boundary (outline) of the petiole section is an irregular shape and as such is difficult to measure precisely. Figure 5 shows how the petiole of a Sabal palm varies in cross section along its axis. The proximal end of the petiole can encircle the trunk and may be an order of magnitude broader than the distal end of the petiole where it meets the leaf blade. For the purposes of the torsion test and because straight samples were required for simplifying the investigation, the most proximal part of the petiole was not tested (a distance of $100 \mathrm{~mm}$ nearest the trunk edge).

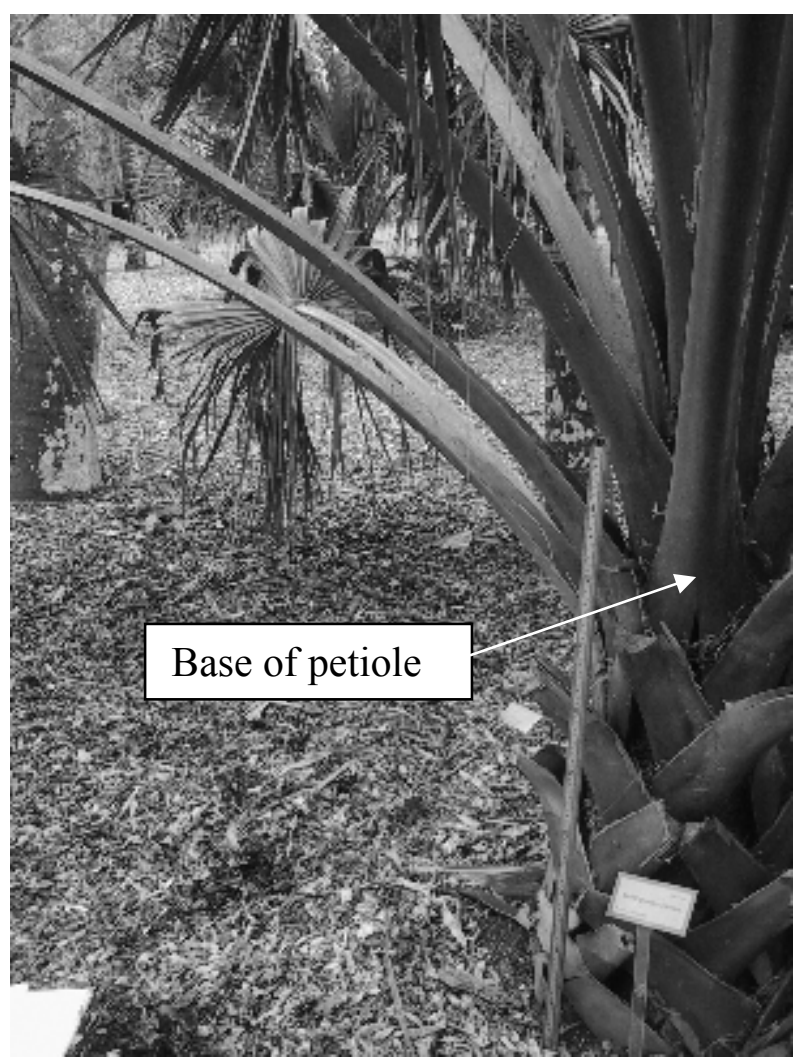

Figure 5: Sabal palm from Fairchild Gardens, Florida showing that the petiole is not of uniform axial cross section.

The remainder of the petiole was tested in segments of similar sectional area (not varying by more than $+/-8 \%$ in area). This effectively enhanced the straightness of each segment. As the petiole segments were to be held in clamps for the torsion experiment, it was important to reduce the effect of clamp ends by keeping the petiole segments as long as possible, so a compromise was made. 
The three segments A, B and C were tested twice in close succession in order to observe the consistency of the data and any hysteresis within the specimen. The specimen however may have partially broken during the first torsion test and this was considered. The outer portion of a specimen is expected to break first during torsion as it is the furthest distance away from the neutral axis.

\subsection{Petiole preparation}

A disease-free petiole of $85 \mathrm{~cm}$ in length was sawn and the cut end of each petiole section was immediately submerged in water to sustain freshness and transpiration. This was so that the data obtained were for specimens that were as much in situ (live) as possible, rather than of a material that had dried out displaying different properties.

Each petiole was divided into five equal lengths of $211 \mathrm{~mm}$ chosen to be the same lengths as the botanical segment samples. Only the first (section A), third (section B) and fifth (section C) segments were used for this experiment (fig.1). The specimen length was chosen as a compromise between minimising the effect of the clamp ends and minimising the section variation along the petiole.

As $20 \mathrm{~mm}$ of each segment end was embedded in epoxy as part of the clamp, the tested length was a $171 \mathrm{~mm}$ sample as shown in fig. 6 . The shape of each segment end was recorded by tracing around the two profiles with a sharp pencil. Cellulose film was wrapped around each cut end to inhibit transpiration, enhancing the freshness of the petiole prior to it being embedded in epoxy.

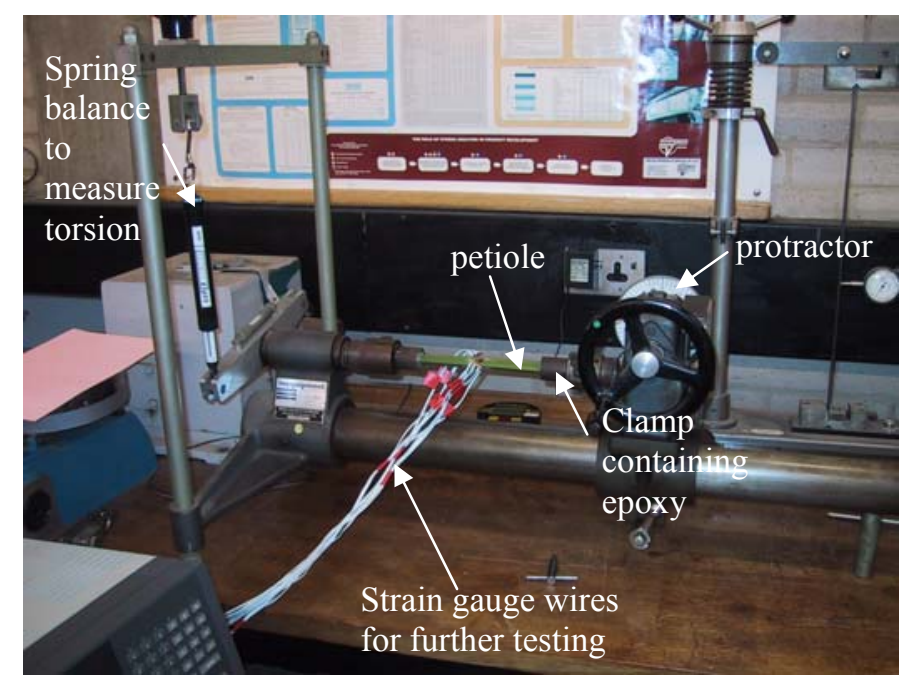

Figure 6: Torsion rig setup showing petiole embedded in the clamps 


\subsection{Torsion data acquisition}

Each segment was set up in the torsion rig after checking the alignment of the machine. In order to calibrate the torsion rig, the protractor was aligned to zero when the spring balance read zero grams. Each end of the petiole was embedded in a machined mild steel receptacle of epoxy resin (by $2 \mathrm{~cm}$ ), the former being clamped to the torsion rig. The clamp receptacles were degreased with FKS UN3295, a non-alcoholic, fast-evaporating solvent to help prevent slippage. As the petiole section was not circular, it held fast within the epoxy resin. After the experiment, the petiole looked intact externally to the naked eye. Data for axial torque and angular twist were manually recorded at ten second intervals simultaneously twisting the segment through one degree for each reading using the rig protractor shown in Figure 6. This experiment was repeated to check the results albeit on already twisted segments and the time lapse between the repeated action was noted. As the petiole was symmetrical about the central vertical plane, it was only necessary to apply torque in one direction. The torque was applied by turning the handle that was fixed to the protractor shown in Figure 6. From cutting the sample to taking the last reading, the first tests took less than two hours. Three samples were tested and these were each from different but similar sized petioles. These were named segments A, B \& C which can be identified in figure 1. The segments were not all from the same petiole as while the first segment was being tested, the others would have tended to dry out, affecting the results. Again there was a trade-off this time between the state of hydration of the petiole and the difference, mainly in shapes, of the three different petioles. Three strain gauges shown in figure 6 were affixed for further testing. The FRA-2-11 type gauges were attached with Araldite 2012 resin to the top and the two under surfaces of the petiole at the same axial position after the surface had been dried and abraded. The gauges were then soldered onto the connecting wires of the data logger. Each strain gauge measured the strain in three directions (0, 45 and 90 degrees) and the data were sent to a Schlumberger SI3535D data acquisition system and analysed using Scorpio v3470 software.

\subsection{Torsion results}

Fig. 7 shows that for both the first and second tests, the torsion readings for segment A were nearly twice those of the other two segments B and C.

For each segment, the torsion readings vary linearly with the angle of twist although this rate decreased slightly with increasing angles of twist. The change in torsion readings per unit time would vary depending on time intervals between angular twisting increments and in this case it was ten seconds.

The part of the petiole nearest the trunk is about twice as resistant to torsion as the central and distal parts.

For all of the segments, there was a time interval of ten minutes between the end of the first and the start of the second test. It can be seen from these results that section A nearest the trunk is the only one to display either strain hysteresis through plastic deformation or permanent damage. 


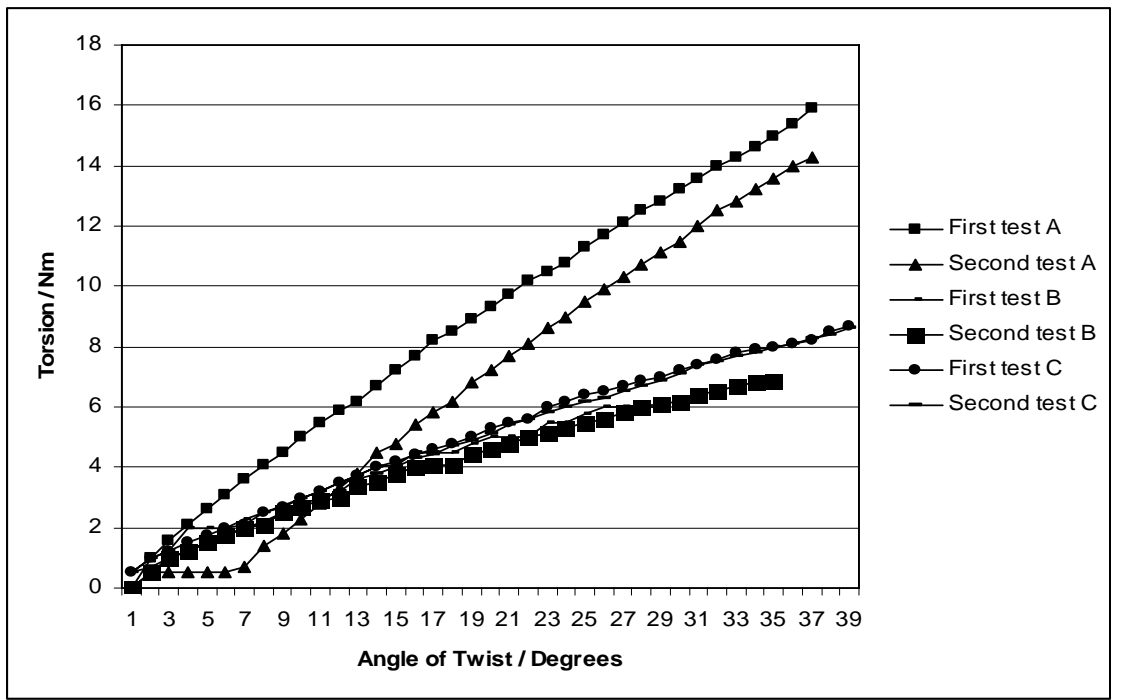

Figure 7: Results of both first and second torsion tests. Readings were taken at a rate of turning of one degree every ten seconds

\subsection{Analysis of torsional rigidity}

The standard equations for torsion of a homogeneous segment are shown in eqn. (1) and have been applied with assumptions, namely that the petiole was not cylindrical or homogeneous. It constituted vascular bundles embedded in a relatively weak, but supportive parenchyma matrix, the latter functioning like packing material. Additionally, the vascular bundles were not distributed evenly throughout the petiole cross section, but were concentrated more towards the external extents of the petiole section and towards the base of the petiole. The concentration of vascular bundles also increased distally, towards the leaf blade. Externally, the petiole was not circular in cross section, but was irregular although symmetrical in the vertical plane. The petiole section varied irregularly along its axis and the cross section area decreased distally.

Applying the standard equation:

$$
\mathrm{T} / \mathrm{J}=\mathrm{G} \theta / \mathrm{L}
$$

Where $\mathrm{T}$ is the applied axial torque, $\mathrm{J}$, the polar second moment of area, $\mathrm{G}$, the torsional rigidity modulus, $\theta$ the angular twist and $\mathrm{L}$ the specimen length.

The torsional rigidity modulus was calculated for each segment using the slope on the plot of the torsion versus angle of twist (fig. 7) and re-arranging 
equation (1). The segment end profiles were scanned and transcribed into a CAD package (Rhinoceros ${ }^{\circledR}$ NURBS modelling for Windows) enabling the area, centroid, second moment of area and polar second moment of area $(\mathrm{J})$ to be processed accurately. The results are shown in fig. 8.

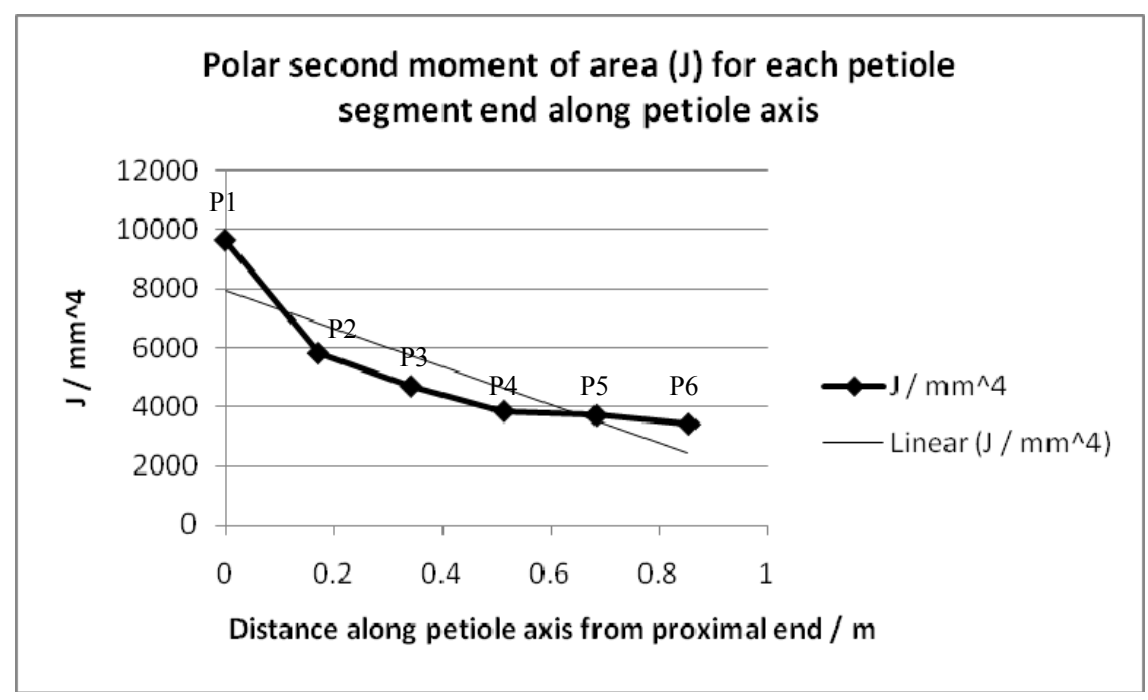

Figure 8: Polar Second Moment of Area $(\mathrm{J})$ for each petiole segment end profile along the petiole axis from proximal end

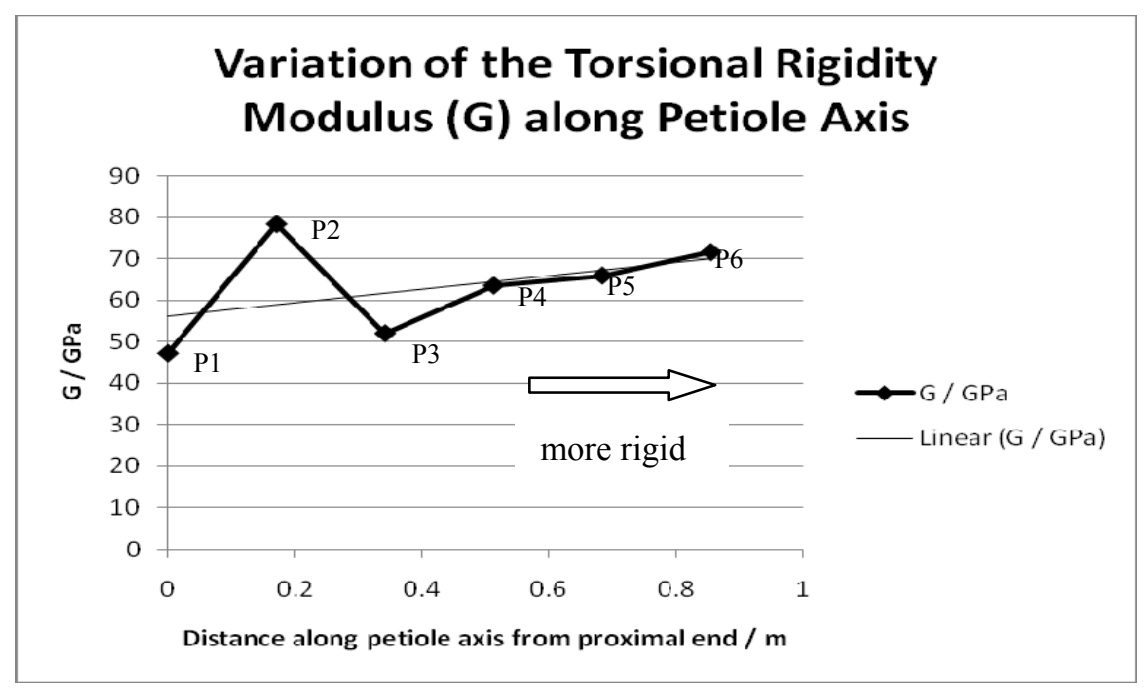

Figure 9: Torsional rigidity modulus along the petiole axis 
The torsional rigidity modulus, $\mathrm{G}$ is plotted in fig. 9 which shows that this is at its lowest at the end of segment A nearest the palm stem. The rigidity modulus, G or shear stress modulus is the ratio between shear stress and shear strain [6]. The mean values of $\mathrm{G}$ for each segment indicate that the torsional rigidity modulus generally increases and is therefore most rigid towards the leaf blade.

\section{Trachycarpus fortunei empirical data of resistance to torsion versus shape factor data}

Shape factor data were obtained for several palm petioles [7] including Trachycarpus fortunei to investigate how much external petiole shape contributes to the torsional rigidity of the petiole. The petiole end profiles were scanned and transcribed into a CAD package (Rhinoceros ${ }^{\circledR}$ NURBS modelling for Windows) enabling the area, centroid, second moment of area and polar second moment of area to be evaluated accurately. These models were then transformed into dimensionless geometrical shape factors, thereby normalising and isolating the section shape of the petiole.

To test the procedure, some of these properties were calculated manually. The profile images were rotated as much as possible to make the adaxial surface symmetrical about the y axis (Fig. 10) and promote accurate calculations of vertical flexural shape stiffness.
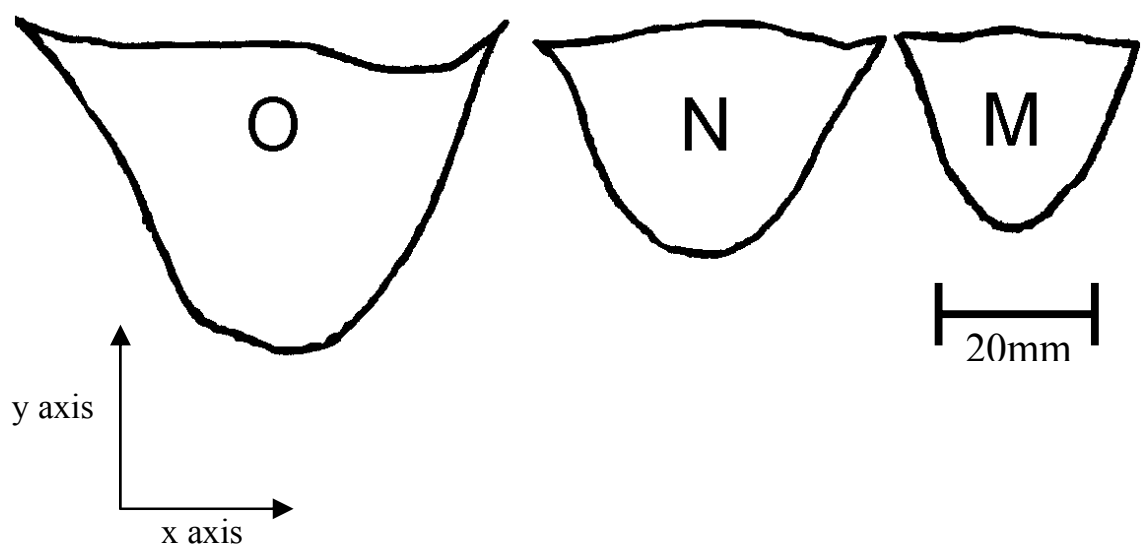

Figure 10: Examples of palm petiole profiles M, N \& O 


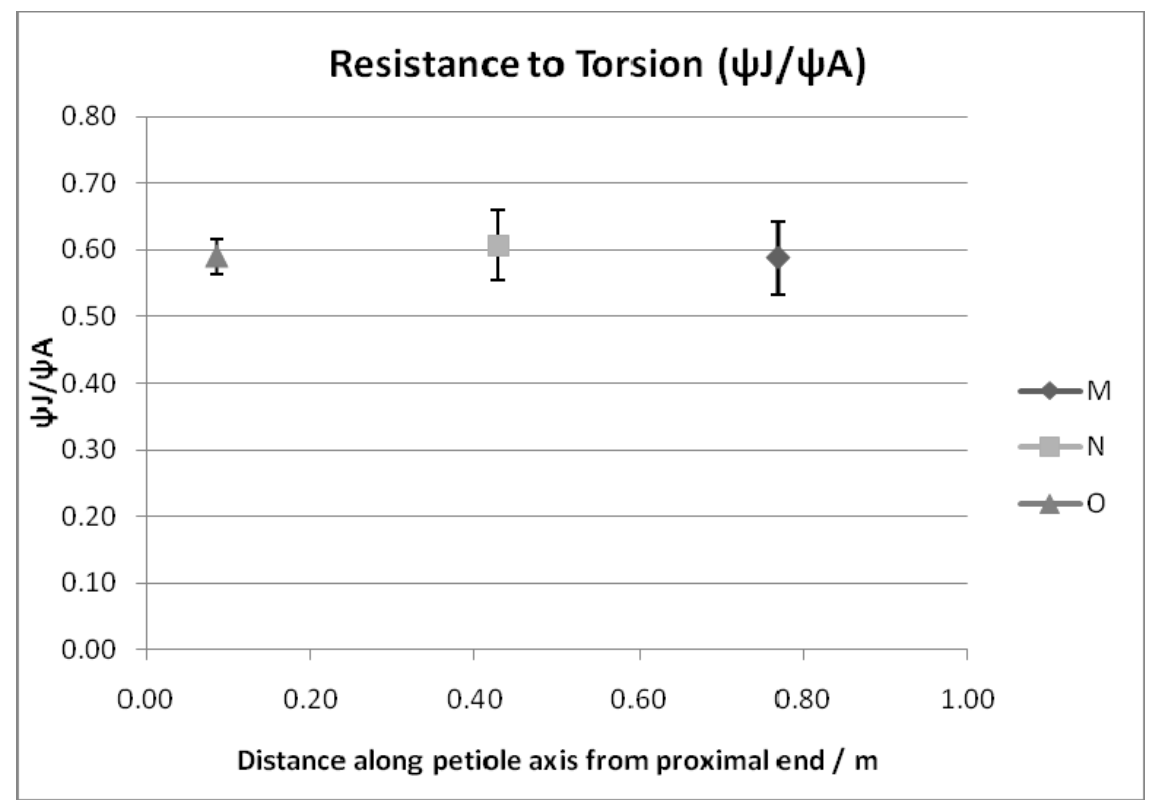

Figure 11: Sample mean values of resistance to Torsion resulting from shape factors alone for petioles from the Trachycarpus fortunei palm. Data were taken four times from the same petiole and confidence levels show 95\% (Table 1). The symbols for resistance to torsion are described as follows:

The shape factor for petiole cross sectional area A, corresponds to the smallest rectangle, $A_{D}$, that will enclose its shape. The following shape factors apply:

$\psi_{\mathrm{A}}=\mathrm{A} / \mathrm{A}_{\mathrm{D}}$ for area

$\psi_{\mathrm{I}}=\mathrm{I} / \mathrm{I}_{\mathrm{D}}$ for second moment of area

$\psi_{\mathrm{J}}=\mathrm{J} / \mathrm{J}_{\mathrm{D}}$ for polar second moment of area

\begin{tabular}{|l|l|l|l|l|l|r|}
\hline & $\begin{array}{l}\text { Distance (m) } \\
\text { from proximal } \\
\text { Section }\end{array}$ & Mean $\psi \mathrm{J}$ & $\begin{array}{l}\text { Mean } \\
\psi \mathrm{A}\end{array}$ & $\begin{array}{l}\text { Mean } \\
\psi \mathrm{J} / \psi \mathrm{A}\end{array}$ & Mean SD & $\begin{array}{l}\text { Confidence } \\
\text { Interval } \\
(95 \%)\end{array}$ \\
\hline $\mathrm{M}$ & 0.086 & 0.353 & 0.600 & 0.588 & 0.056 & 0.054 \\
\hline $\mathrm{N}$ & 0.428 & 0.368 & 0.606 & 0.607 & 0.053 & 0.052 \\
\hline $\mathrm{O}$ & 0.770 & 0.342 & 0.580 & 0.590 & 0.027 & 0.026 \\
\hline
\end{tabular}

Table 1: Average of four repeated resistance to torsion values $(\psi \mathrm{J} / \psi \mathrm{A})$ acquired for each section of the petiole showing 95\% confidence intervals in the measurement error. The confidence intervals increase distally because distally, the petiole was smaller and more inaccurate to measure with the profilers. 
Figure 11 shows that the resistance to torsion for the entire length of the palm remains constant from the shape factor analysis. This contrasts with the empirical data acquired from the torsion experiment where it was found that the petiole was less able to twist towards the leaf blade. This shows that other factors occur to facilitate twisting at the trunk end of the petiole, the external shape of the petiole not being significant in this case.

The internal arrangement of vascular bundles within the parenchyma matrix varies. The petiole becomes more tube-like towards the leaf blade as the spatial density of the vascular bundles increases towards the sides of the petiole. The diameter of the vascular bundles decreases towards the leaf blade.

According to Zimmermann and Tomlinson [8] vascular bundles at the periphery of the palm stem (not the palm petioles) tend to be more vertically parallel compared with those in the centre where they can be found to be helically arranged. Therefore, as well as investigating the macro and micro structure of the petiole, the arrangement of the interior must be taken into consideration also. The tensile strength of dehydrated vascular bundles is remarkable at about $100 \mathrm{GN} / \mathrm{m}^{2}$ [9] so the internal forces within plants are influential.

\section{Discussion and Conclusions}

Analysis of the location and number of vascular bundles [10] at equal distances along the petiole was possible using a scanner with a resolution of $1200 \mathrm{dpi}$. The sections were embedded in wax after removal of slices of the petiole with a microtome.

A higher concentration of vascular bundles was found towards the outer side of the petiole. In the tested section (P6), there were $47 \%$ more vascular bundles in the top vertical half above line XX (fig.3) nearest the adaxial surface compared to the lower half nearest the abaxial surface of the petiole sample below line XX. Further to this, there was $80 \%$ more area of petiole above (adaxial to) line XX compared with that below it. It may be concluded that there is a higher concentration of vascular bundles below line XX, i.e. on the underside of the petiole. This is the part of the petiole most under compression when in normal environmental conditions. However, we do know that vascular bundles have a high tensile modulus of around $100 \mathrm{GPa}$ [5] so perhaps this material is strong both in compression and tension.

The concentration of both the internal and peripheral vascular bundles increases fairly steadily towards the leaf blade although the concentration of the peripheral vascular bundles increases more per unit axial distance than that of the internal bundles. As the number of vascular bundles in section P4 is 330 and that in section P6 is 375, i.e. an increase of $13 \%$ over a third of the petiole length, it is probably the case that the vascular bundles branch distally as with the animal and dicotyledenous plant vascular systems. Constructal branching is commonly found in plants in terms of vascular systems [11] and in this case the branches in the petiole are for the water and nutrients in the vascular bundles to connect the 
trunk to the furthest most parts of the leaf blade (the blade being the source for the nutrients and the sink for the water through transpiration).

The increasing spatial density of vascular bundles towards the leaf blade together with the reduction in cross sectional area of the petiole allows it to become more rigid allowing it to support the weight of the leaf blade.

The first and second torsion test data are very similar for both segments B and $\mathrm{C}$, but differ in segment $\mathrm{A}$ : this indicates that the properties of this segment changed after the first test. Although the material in segment A may have been damaged beyond the point of elasticity the slight convergence of the first and second test plots for segment A in Figure 7 indicates hysteresis to some extent. Plants also have the ability to self-repair [12] allowing any temporal displacement to be closed.

For both the first and second tests, the torsion values for segment A are nearly twice those of the other segments when readings were taken at ten second intervals while being twisted through one degree increments. Segment A was found to be twice as resistant to twisting as the other two sections, possibly as a result of its different arrangement of vascular bundles within and the greater cross sectional area (the shape alone not having a significant effect). The torsion values vary almost linearly with the angle of twist although this ratio decreases slightly with twisting. Perhaps a different relationship would be apparent if the time interval between unit increases in angle of twist changed. The results may be partly due to creep and the small scale elastic adjustment of the petiole material. However, the shape factor analysis shows that the resistance to torsion for the entire length of the palm remains constant contrasting with the empirical data acquired from the torsion experiment where it was found that the petiole became more rigid towards the leaf blade. While the external shape of the petiole is not significant with respect to the change in torsional resistance along the petiole, other factors are significant, for example, the spatial arrangement of the vascular bundles.

Research on the plant's response to mechanical stress has identified mechanosensitive ion channels which regulate the amount of calcium ions entering the cell as a result of stress. Calcium ions probably regulate the first stage in the signal transduction pathway from the first perception of the mechanical stress to the activation of genes which synthesise proteins in response to the stress [13].

For all of the sections, a time interval of ten minutes between the end of the first and the beginning of the second test was set. It is interesting to see from the results that segment $\mathrm{A}$ nearest the petiole is the only one possibly to display partial stress hysteresis. Hysteresis in this part of the material where the cross sectional area of the petiole is largest, reduces damage to it. The repeated movements of the petiole caused by the forces of a prevailing wind are reduced as a result of hysteresis enabling the petiole to temporarily re-shape to the prevailing forces.

Ashby et al [14] found that wood, with its high value of $(E / \rho)^{1 / 2}$, where $E$ is the Young's modulus and rho is density, is well suited to resist both bending and elastic buckling. In addition, palms, although having a 'simpler' structure (which is slightly less efficient than dicotyledonous or gymnospermous woods in 
bending resistance and buckling) is nevertheless stronger in these regards than many engineering materials. This result correlates with what was found when the ten dicotyledons were compared with the seven palm petioles in that, based on median averages, the dicotyledons had a higher resistance to bending than the palms at each point along the palm petiole from a shape factor perspective. This difference was greatest at the point nearest the stem and decreased along the petiole axis to the position near to the join of the blade and the petiole where the flexural stiffness of the palm was similar to the dicotyledons [15].

From this small set of experiments, an insight has been gained into the mechanical behaviour of the Trachycarpus fortunei palm petiole. It is shown to be an efficient structure, economical in materials and well suited to its function. These results consequentially have design implications for manmade cantilevers.

\section{Acknowledgment}

The authors thank Dr. Ian Kill senior lecturer in Human Cell Biology Laboratory of Cellular Gerontology, Brunel University for his assistance with preparation of the petiole specimens.

\section{References}

[1] Gibbons, M., A pocket guide to palms, Chartwell Books, Inc., New Jersey, 2003.

[2] Tomlinson, P.B., The Structural Biology of Palms, First Edition, Oxford Science Publications: Oxford, 1990. Pg 10.

[3] Gibson, L.J., Ashby, M.F., Karam, G.N., Wegst, U \& Shercliff, H.R., The mechanical properties of natural materials. II. Microstructures for mechanical efficiency, The Royal Society, London, 1995.

[4] Windsor-Collins, A., Cutler, D., Atherton, M. \& Collins, M., Design and Information in Biology, 'The palm - a model for success?' Chapter 10: 303-326, WIT Press, Southampton, UK, 2007.

[5] Niklas, K.J., Plant Biomechanics: An Engineering Approach to Plant Form \& Function, First Edition, The University of Chicago Press: Chicago, 1992.

[6] Rees, D.W.A., Basic Solid Mechanics, Macmillan Press Ltd., Basingstoke and London, 1997.

[7] Pasini, D., Shape Transformers for Material and Shape Selection, ASME DETC-84894, 2005.

[8] Zimmermann, M.H., and Tomlinson, P.B. The vascular system of monocotyledonous stems. Bot. Gaz. 133:141-55. 1972.

[9] Niklas, K.J., Plant Biomechanics: An Engineering Approach to Plant Form \& Function, First Edition, The University of Chicago Press, Chicago, 1992.

[10] Windsor-Collins, A., Atherton, M., Collins, M. \& Cutler, D., 'Structural and torsional properties of the Trachycarpus fortuneii palm petiole', Design and 
Nature III: Comparing Design in Nature with Science and Engineering. Pg 185, WITPress, Southampton, UK, 2006.

[11] A. Bejan and S. Lorente, Constructal theory of generation of configuration in nature and engineering, Journal of Applied Physics, Vol. 100, 041301. 2006

[12] Mattheck, C. \& Tesari, I., Uniform Stress - A Design Rule for Biological Load Carriers, Institute of Materials Research II, Design in Nature Pg 217, Forschungszentrum Karlsruhe, Germany, 2003.

[13] Elliott, K.A. and Shirsat, A.H - Extensions and the plant response to tensile stress. Society for Experimental Biology Conference. J. Exp Bot Vol 49 p 16. 1988.

[14] Ashby, M.F., Gibson, L.J., Wegst, U \& Olive, R., The mechanical properties of natural materials. I. Material property charts, The Royal Society, London, 1995.

[15] A.G.Windsor-Collins ${ }^{1}$, M.A.Atherton ${ }^{1}$, M.W.Collins ${ }^{1}$ \& D.F.Cutler ${ }^{2}$, Section properties of palm petioles, Part 1: The influence of section shape on the flexural and torsional properties of selected palm petioles, Design and Nature Journal, WIT Press, Southampton, UK, 2008. 